\title{
What does it take to deliver an active hands-on course?
}

\section{Dr. Steve C. Hsiung, Old Dominion University}

Steve Hsiung is a professor of electrical engineering technology at Old Dominion University. Prior to his current position, Dr. Hsiung had worked for Maxim Integrated Products, Inc., Seagate Technology, Inc., and Lam Research Corp., all in Silicon Valley, CA. Dr. Hsiung also taught at Utah State University and California University of Pennsylvania. He earned his BS degree from National Kauhsiung Normal University in 1980, MS degrees from University of North Dakota in 1986 and Kansas State University in 1988, and PhD degree from Iowa State University in 1992. Steve can be reached at shsiung@odu.edu.

\section{Dr. Feng Jao, Ohio Northern University}

Feng Jao, Ph.D., is an Associate Professor of Educational Technology at Ohio Northern University. She has been teaching courses in the area of Computer and Information Technology. Her areas of interests include Hybrid Learning Instructional Design, Digital Media, Interactive Media, Instructional Technology Integration and network design. In addition, Dr. Jao is a certified Microsoft Office Master Instructor, and Cisco Certified Network Associate (CCNA). Her current research activities are web standards, responsive web design and network design. She is an active member of ITEEA, ATMAE and other professional organizations. Dr. Jao can be contacted at f-jao@onu.edu 


\section{What does it take to deliver an active hands-on course?}

\section{Introduction}

The cyber enabled learning takes many shapes and forms. It is commonly described as Distance Learning, Hybrid Learning, eLearning, or on-line learning ${ }^{1}$. Whichever terminology that is used, Internet based assistant learning can be used as a standalone online instruction or as in conjunction with traditional face-to-face instruction. This learning environment offers not only real-time distance learning experience but also provides learners the availability of asynchronous course materials that assist learning $24 / 7$ via archived database ${ }^{2}$. It offers wide range of opportunities in the on-line learning community, for not only between teacher and students, but also among students. In addition, it allow educators' to collaborate in distance despite of geographical locations, share experiences, develop programs, collaborate in researches, and improve faculty professional development. With the rapid change of the Internet and available technologies in teaching and learning tools that provide opportunity to implement online courses, and allow static and dynamic feedbacks from students and other teachers to better assess the outcomes of the course in many aspects such as students' performances, teachers' technical knowledge, teaching skills, and effectiveness in course delivery. Cyber-Enabled Learning is a trend of teaching methodology for the younger generation. It is an alternative and can be used concurrently with face-to-face on campus learning environment and not necessary as a replacement of the traditional learning ${ }^{3}$.

\section{How active learning can be conducted in distance learning (cyber learning)?}

Active learning provides opportunity to engage learners in activities. Active Distance learning provides a real time interaction between students and instructors and occurs much the same as in a regular classroom; however, students are not in face-to-face contact with instructors. Active distance learning environments typically capitalize on high-speed Internet connections using televised lectures and demonstrations via satellite connections, video streaming, or conferencing applications. Typical streaming, collaboration, and conferencing applications include Adobe Connect Pro, MSN Messenger, Yugma, iPod/iPad, Google Chat, Skype, Facebook, YouTube, and others are typically utilized in the on-line teaching environment ${ }^{4}$.

\section{Couse Delivery Methodologies}

\section{Synchronous/real-time lectures}

Planning, designing, and implementing active learning in a distance education environment is similar to those activities for traditional classes except that planning for courses without faceto-face contact makes the design process particularly important. To implement an active distance learning environment requires the coordination and correlation of instructional materials, media, and technology. Correlating real-time lectures with audio and video are one of several very important elements to the success of the distance learning. The outcomes of the distance learning class should be the same or similar to a traditional lecture/laboratory class. There should be little or no difference between an instructor's face-to-face classroom lectures, except instructional materials are accessible in electronic formats for users to download. Notes, handouts, graphs, photos, demos, circuits, equations, software shall be displayable on a computer terminal and available to students viewing during the lecture. Software applications that students need in order to complete the online course such as Paint, 
Visio, Microsoft Office, Multisim, MPlab, MATlab, and etc. should be available as freeware or as student versions at a reduced cost. All the material shall be available to students before the scheduled lecture period and encourage students have a hardcopy and pre-view before the lecture.

\section{Study guides and other print media resources}

Study guides and other print media resources should be provided along with any software and hardware that students need to use for class lectures and laboratory exercises. Any supporting materials such as data sheet, reference books, and URLs (Uniform Resource Locators) of online resources should be identified for students before any assignment or exercise is issued.

\section{On-line discussion forums}

Discussion forums add to the active dimension of the course. On-line forums allow active interaction among users. They can share and assist others in topics that they have difficulty with. On-line forums should be designed for students as a learning resource center for questions and answers, learning lessons, difficult issues, and experience sharing (not assignment answers or software/hardware project results). Every student is required to participate in the discussion forums. The participation from the students can be counted as class attendance. Instructor acts as a moderator, and must closely monitor forum activities to ensure rules are followed, resolve conflicts if any, and edit/delete posts if needed. Each class member can post questions and comments as well as answer questions. The discussion forum provides students with anytime anywhere resources to learn the course materials. It can also ease the load of the instructor from repeating the answers to the same or similar questions posted by different students.

\section{Scheduled learning progress checks on weekly basis}

Scheduled instructor-student meetings with each individual student on a regular basis are an important dimension of a quality distance learning environment. Scheduled student-teacher meetings, usually weekly, are required to ensure the integrity of the distance learning process, maintain student focus, and improve student retention. This also provides closely monitored progress of the student's learning progress. One-on-one meetings provide an excellent opportunity for the instructor to know every student in class and provide additional assistance to those who are in need. This setting is also an opportunity to review the performance of the required assignments, homework, laboratory exercises, and projects.

\section{Individual help sessions in real-time}

Extra one-on-one meetings can be arranged for any special need student. This is the same format as office hours for on-campus students. An appointment through e-mail or telephone is required to schedule a help session. The instructor can also require one-on-one meeting, as appropriate, if evidence of drift away/side track in a student is found.

\section{Archived lessons}

Distance learners often are non-traditional students, and often have more responsibilities outside of classroom in comparison to traditional on-campus students. Accordingly, all the real-time on-line lectures, group discussions should be archived and available to every 
student. Anyone that missed a session is required to view the archived within 24 hours. This also provides resources to the students who are still unclear about class lectures or discussion topics, and it can also serve as a resource for review. In addition, it can act as verification resources between instructor and students to clear any dispute, if there is any.

\section{File Servers and Online Learning systems}

A key component regarding on-line courses is the accessibility of course materials. It depends on the campus network setup. Users need to setup their private account prior to sign up the course. Instructor can make course materials available on campus network, and allow user access through VPN (Virtual Private Network) connection and map to campus network drive. An alternative to this method is to use a Learning Management System (LMS) to host online course materials. Moodle is a widely used (LMS) tools to manage online course materials. It provides critical functions needed for active learning experience such as discussion forums, on-line relay chat, demo videos, and etc.

\section{Common Hardware and Software Platform}

Common platform is the key success to the implementation of the active STEM related distance learning classes. Electrical and computer engineering technology courses require activities involve hardware devices, circuit designs, and software designs in various levels. If there isn't a standard platform for everyone (students and instructor) to use, there will be too many variations. Without a common hardware platform, it is almost impossible for instructors to assist learners to trouble shoot and solve/assist project difficulties. These will be even harder and time consuming for instructors to assist students with special needs. A common hardware platform will reduce confusion and will be earlier to control issues occurred during problem solving ${ }^{6}$.

\section{Laboratory Simulations}

Computer simulations may be made to reduce the load of hardware uses. A proper network setup will resolve the software license issue. Regardless, how real the software simulation is, there are still needs to do the hardware experimentations to bridge the gap between theory simulation and real life applications.

\section{Laboratory kits}

To resolve the hardware common platform issue, a commercial available laboratory kits may be used for the laboratory exercises. The cost of the kit needs serious evaluation that could be an obstacle to the recruitment of distance students. A custom made hardware platform that fits for academic special needs with a very reasonable cost is the core element to the success of the engineering related distance learning.

\section{Assessments - Formative and Summative}

\section{Performance assessment - Examinations}

On-line distance course should be the same as traditional face-to-face instructional design, Performance Assessment (PA) is important in determining if learners have achieved the learning objectives for the subject area. Standard course examinations are major components of the assessment process. PA can be conducted during the semester; it serves as a formative 
evaluation of the course. Instructors can evaluate the outcomes of the formative assessment to modify their teaching strategies, and implement different types of online activities to improve the course. A summative evaluation can be conducted at the end of the semester to major the overall course outcomes. Methods of Assessment vary; the examination questions can be available online during scheduled examination times. By making the examination opened book/opened notes will eliminate the need of a proctor and an exam center to conduct the assessment. Students can submit the exam back to the instructor in an electronic form or if fax is feasible. If a closed book examination is necessary, then a proctor and examination location should be resolved between course offering intuition and a local school in the distance learning network. An on-line real-time monitoring system can also be used for the closed book exams. Examination questions should reflect the course objectives.

\section{Weekly performance check on laboratory assignments}

Means need to be designed so that faculty can review the activities or laboratory results that students need to complete. This will require weekly performance checks on laboratory assignments. One way to do this is to schedule one-on-one sessions between students and the instructor. This can be done with an on-line chat, telephone conversation, or a two way video conferencing using computer software applications that the faculty can view students work via a webcam.

\section{Laboratory review test questions}

Reviews for testing can also be undertake using a chat room format, where students would send in questions via email and the faculty member can review these in chat sessions.

Another way would be to have the class divided into groups where students would communicate with each other. A team leader is assigned to each group. He/she can organize the communication within the group. Instructor monitors and provides answers or cues to the group members who do not know the answers. The team leader role must be rotated within the group to distribute the duties among the team members. This method would save time spend on on-line chat. Evaluate the team leader with associated team members' performance scores will motivate the leadership and activities that lead to better performance on everyone.

\section{Laboratory project demonstration and written reports}

Where laboratory projects are needed to assess student learning outcomes, the projects must be checked by the instructor. If the webcam capabilities exist, instructors can view students' works and have them demonstrate the operation of circuits/hardware and software designs. The faculty member can use this technology to trouble shoot circuit designs and assembly. If this communication mean is not available to students, alternative methods must be found to assist possible trouble shooting via regular mail. Finally, the projects must be sent back to student so the instructor can help to identify the problems.

\section{Homework assignments}

Homework assignments should be assigned to measure student achievement. It is recommended that these be set on the course schedule, so there is an adequate time for the instructor to receive, evaluate, and return in a timely manner. These can be posted on-line

and students can send them to the faculty electronically or submit the files through LMS such as blackboard or Moodle or through VPN or FTP (File Transfer Protocol) campus network 
drive. It is important to keep strict deadlines for all assignments. It allows learners to keep up to the path, and also remind the instructor, not to get into too many assignments at the end of the course and not have sufficient time to evaluate them.

\section{NSF Sponsored Workshops}

All the above mentioned practices in real-time and hands-on distance delivery and oncampus offer of the microcontroller courses have been implemented at ODU since 2009 in EET320, EET325, and EET470 that are related to the embedded system designs and applications in junior and senior levels. The students' performance in distance classes performed better than the counter part of the campus students ${ }^{5}$. After the proof of concept implementations of the synchronous, real-time, hands-on distance delivery of the embedded system design courses at ODU during the years of 2009 to 2012, a full PIC training system and curriculum package have been designed and developed. With the assistance of the NSF TUES type 2 grant in 2013 and 2014, a series of 6 distance training 3-day workshops in 3 different regions nationwide have been implemented for 2- and 4-year faculty and high school teachers in better teaching and learning of the embedded system with PIC microcontroller. The following section describes the workshop conducted during the summers of 2013 and 2014.

\section{Active Online Distance Learning for NSF Sponsored Summer Workshops in 2013 and 2014}

Prior to the workshop, the researcher team realized that in order to deliver the subjects/courses successfully in an on-line learning environment, common instructional materials and tools must be made available to all learner despite their geographical locations. To overcome the issue, researchers have designed and developed a common hardware platform, a trainer board, to deliver this technical based subject. This trainer board allows all participants to have the same technical learning environment. In this project, a PIC training system was designed through the support of a previous NSF supported grant. The refined microcontroller laboratory board includes the following features:

All component parts are available from vendor purchases.

1. The system could be used with Microchip (PICKit2, PICKit3) ${ }^{7}, \mathrm{NXP} /$ Philips (LPCX) $^{9}$, and Ardunio systems for programming, simulation operation, and debugging.

2. Power options include $+-5 \mathrm{~V},+-12 \mathrm{~V},+3.3 \mathrm{~V}$, digital and analog $\mathrm{I} / \mathrm{Os}$, LCD, and LED displays, RS232 and USB communication capabilities, $2.4 \mathrm{GHz}$ wireless module, and high and low power isolation for digital/analog and motor drive controls.

3. OPAmp, EEPROM, DAC operations, and SPI Bus are accessible.

4. FET/IRF530*8 power for stepper and DC motor controls are available ${ }^{5}$.

The design of a common instructional platform played a significant role in eliminating troubleshooting technical issues in teaching practical hands-on technical courses ${ }^{4}$. Teaching and learning processes become much more convenient and feasible in the distance learning environment. Both instructors and workshop participants share the same equipment which made the communications among participants and the instructors much easier. In addition, it is easier for users in troubleshooting hardware devices and the software design with different programming languages. This training system was also designed by the researchers' with affordable budgets in mind. Learners do not need to purchase any additional textbooks or laboratory manuals because the instructional materials were developed to go along with this 
system were written and posted on a server for workshop participants to access by the research team. The design and development of this common platform would make this project successful in teaching and learning microcontroller through distance learning ${ }^{5}$. Photo 1 shows the PIC training system that was designed and used in these project implementations. Photo 2 is the PIC Trainer used with Arduino Module.

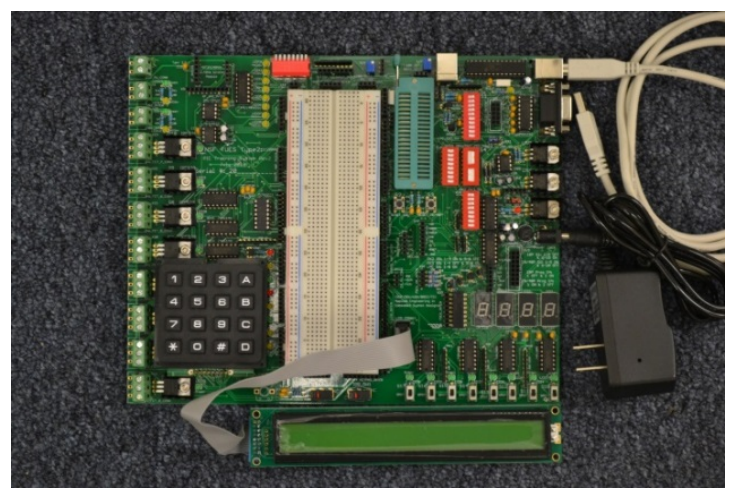

Photo 1. PIC Training System

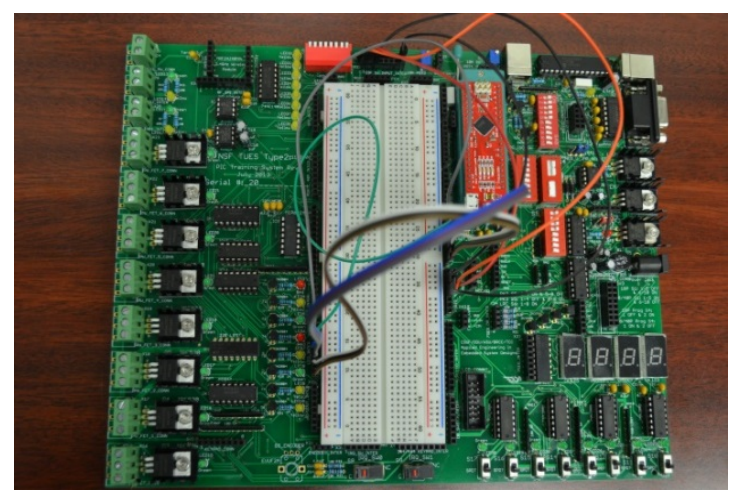

Photo 2. PIC Trainer with Ardunio Module

In addition to the development of the trainer board, researchers also developed curriculum modules, laboratory modules, and customized application software, and demo videos to deliver these on-line based instructions.

\section{Asynchronous On-line Instructional Methods}

Several mechanisms were used to deliver these on-line instructional materials. Web portal is one way to deliver the instructional modules. Prior to the workshop, the trainer boards were shipped to all the participants and a resource web page (http://www.ucdistancetraining.org/ preworkshop.php) were developed with information that users need. Resources in the website include software applications such as initial trainer test, MPLAB IDE, XC8, PICKit2 ${ }^{7}$, Arduino, and PIC Training System manuals. Learners need to setup and test these software applications with their trainer boards prior to the workshop. Instructional materials for setting up and testing the training board were provided through the online webpage. In addition, instructions for using online video conference were provided in the page for learners to setup their audio and video equipment. Multiple real-time pre-workshop training sessions were available to participants to choose to learn about the on-line tools and the environment before the start of the workshop. Everyone is required to attend the pre-workshop training before one is allowed to participate the 3-day workshop activities.

Server storage setup and access account issues was investigated, where learners can use the centralized service to download and upload course materials. Some researchers choose to use their campus servers, while others choose to use Blackboard or similar LMS operated by their schools. This research team needed the capability to have all project faculty members capable of uploading content from their institutions and have plans for others who want to post shared materials related to microcontroller technologies onto the server. University servers have restricted access and firewalls to protect their servers from outside users. This project had to allow access for users from outside of the university domain. In addition, the research team wanted to post videos that supported microcontroller instructional materials, and laboratory demonstrations. This also required the posting of programming code, so users could download them for their microcontroller design functions. In order to accomplish all the needs and have a centralized file 
sharing location, the use of Moodle is appropriate to this project. Moodle is an open source LMS that can deliver all the course materials to the participants. Although Blackboard and Moodle merged in April 2012, Moodle remains an independent division and continues to serve the educational community in an open source format. The project team purchased a hosting server to host the Moodle service and the web portal. The centralized location allows users to have an access account to view, download and share course information. Shared Moodle modules at http://www.ucdistancetraining.org/moodle/ include but not limited to the following: pre-workshop materials, pre-recorded presentation videos, Lab videos, course instructional material modules, laboratory modules, laboratory programming codes, workshop lecture archives, laboratory assignments, and discussion forums. Figures 1 and 2 demonstrate the LMS Moodle designs.

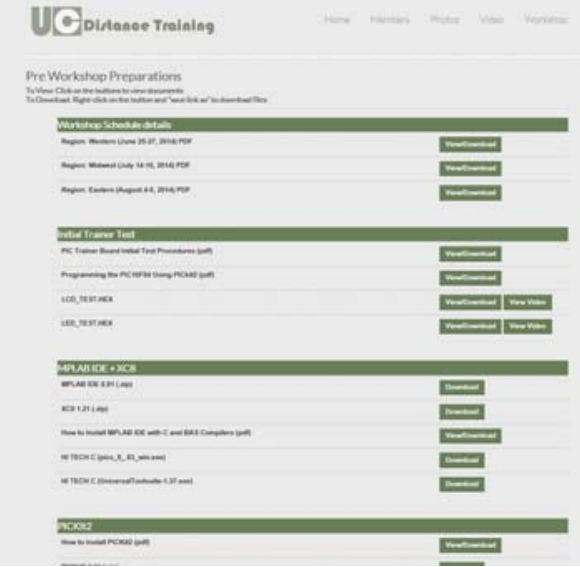

Figure 1. Moodle - Pre-workshop Reference

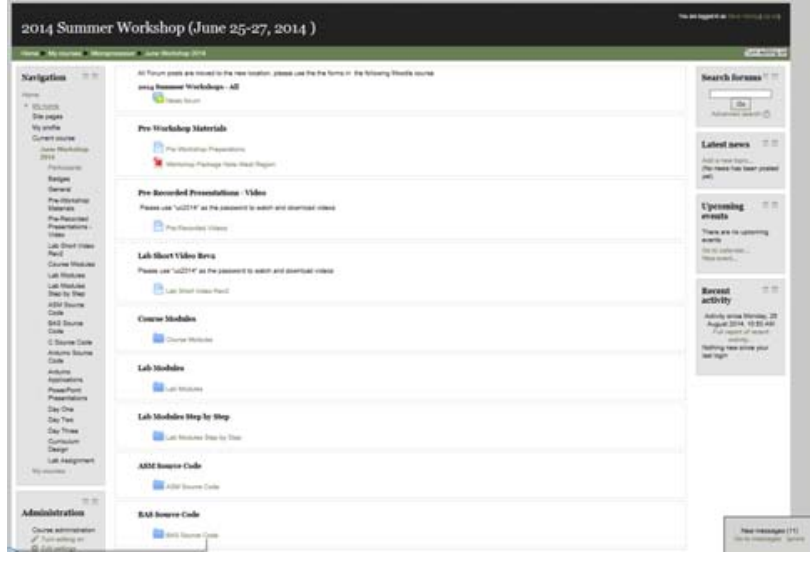

Figure 2. Moodle Server Setup

\section{Synchronized Online Instructional Methods}

The research team also had to choose how they plan to deliver courses via distance learning technologies. Faculty had experience with web-posting of course materials, with active distance learning theories in mind; they sought to make the project more interactive in delivery mechanisms. This means the courses must be offered real-time; with the instructors interact with workshop participants directly in video conferencing format ${ }^{8}$. The researchers had worked with Adobe Connect using real-time distance lectures, conducting laboratory exercises, video conferencing, and creating audio/video archives. The Adobe Connect server is hosted at ODU and three faculty had taught students using the system. Adobe Connect became the technology the faculty research team used to hold monthly meetings. Each faculty member in the research team was trained to use this conferencing system at a 2-day special training and then required to use it in monthly research team meetings. Advantages of this system include its video and audio capabilities. Audio can be controlled and, when desired, students click on an application function requesting permission to speak. The instructor is in control to allow workshop participants' conversation which reduces possible audio chatter. This system also allows the instructor to focus one of the video cameras onto the trainer board, so learners can see wiring configurations and watch demonstrations. The video conferencing application also allows faculty to divide the class into sections, so different groups of students can conference (collaborate) with each other.

With the assistance of the Adobe Connect real-time video conferencing flexibilities, the main lectures/presentations were done in the main virtual classroom, where they were taught by different research team members. The laboratory sessions were broken into different subgroups/virtual laboratory rooms for different software designs in Arduino, Assembly, BASIC, 
and $\mathrm{C}$ programming languages and hosted by different research team members. This allows the preference of programming language from the workshop participants while still keep the teaching and learning subjects consistent. Another function that Adobe Connect has is its ability to allow for the recording of all training sessions/classes. Faculty can select to record each class session and then post the saved content at a generated URL. Later, the faculty can share the URLs with students for their review. This allows students to use the video recording when they are conducting laboratory activities while away from the courses hours. It also allows the faculty member to pre-record a class session if they need to miss class. Photo 3 is a presentation of the real-time Adobe Connect video conferencing. Photo 4 presents the real-time sharing, demo, and trouble shooting.

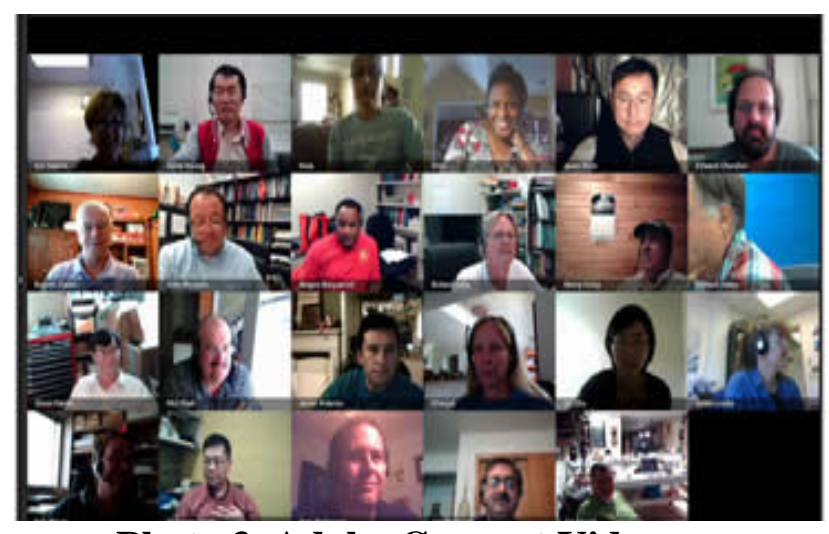

Photo 3. Adobe Connect Video Conference

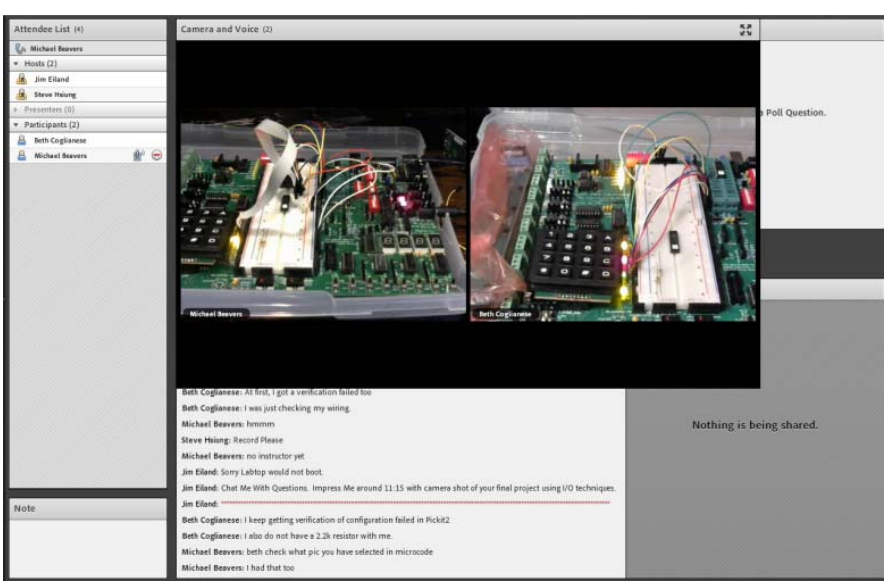

Photo 4. Real-Time Demo and Trouble Shooting

\section{Assessment}

Due to the limited duration of these summer workshops, research team was only able to assist participants to utilize active on-line learning activities such as posting competed project videos online for group review, on-line chat among peers to problem solve the projects and etc. In addition, the team also gathered assessment data at the beginning and the end of the workshops to support the effectiveness of these workshops.

To determine the knowledge of participating faculty in microcontroller topics before the training began, a pre-test was administered with the Pretest mean $=4.99$. After the completion every workshop the post-test was given and its Posttest mean $=14.85$. There are total of 6 different workshops implemented in 3 different regions nationwide in summers of 2013 and 2014. The total tested population $=117$ and the total participation $=125$ where there are some are students or sit-in observers (retired educators, hobbyist, physicians, industry personals, and some dropped in a short notice for family reasons) who are not qualified for this project's proposed target audiences. There are cases some of the participants who repeated the workshop training simply want to learn more programming language designs. Those special cases were taken out of the total population calculations in the Posttest scores. Course module goals and objectives were used as the base to create the testing questions. Total of 22 questions were created and used to measure the effectiveness of the distance workshop implementations. Test results showed that on an objective test from the content chosen for this training, little was known about microcontroller concepts before training and sufficient learning did take place through the distance delivered instructions. This finding supported the intended outcomes, and proved the effectiveness of the workshops. 
On the other hand, survey questions were conducted at the end of workshops to obtain learners' responses and feedbacks to better improve the subsequent workshops. Learners expressed various active teaching methods such as on-line reading materials, posted lectures, video demonstrations, hands-on laboratories, and various communications means (relay chats, forum discussions) help them engaged the workshop more. As some of the feedbacks shown below:

Overall, fantastic! I enjoyed it. The readings helped. We could do more programming if there were more time. I never learned so much in just 3 days. Please send my thanks to all of the presenters and helpers who made it work so well.

I enjoyed the class. Instructors were well prepared. I want to try conducting an on-line lab myself in the future.

I wish there were more workshops like this available. I learned a lot without needing to travel. It was not just a bunch of fluff and waste of my time like some workshops I have attended. Very well done and lots of effort by instructors.

-by 2014 workshop participants

The research team concluded that this is an effective approach for instruction in technical fields related to microcontroller programming and interfacing. The workshops were very smoothly run and effective. Perhaps these techniques will be useful for other technical fields as well. The team has demonstrated the efficacy of remote hardware laboratories monitored via distance education, a major goal of the project.

At the time this article is written, the PIC training system and curriculum have been successfully adopted at ten different institutions: (1) Virginia State University, Petersburg, Virginia, (2) State Technical College of Missouri, Linn, Missouri, (3) Rock Valley College, Rockford, Illinois, (4) Blue Ridge Community College, Meyers Cave, Virginia, (5) Tidewater Community College, Chesapeake, Virginia, (6) Bellingham Technical College, Bellingham, Washington, (7) Thomas Edison Sate College, Trenton, New Jersey, (8) Wentworth Institute of Technology, Boston, Massachusetts, (9) Wayne State University, Detroit, Michigan, and (10) Prairie View A\&M University, Prairie View, Texas.

\section{Conclusion and Recommendation}

Although cyber enabled learning provides many benefits to learners, it is important that educators investigate the teaching needs, activities, modules, available technological tools and supports to make the online classroom compatible to standard face-to-face on-campus classes. This article investigates the concept of active learning for online courses including the delivery methods, common hardware and software platform, assessments, and course evaluation. In addition, authors also reported workshops conducted using the theories of active online learning in the field of microcontroller embedded systems.

The overall goal of this project was to create an on-line learning community for faculty members nationwide. Active on-line learning environment allows the team to achieve the goals. Many faculty members have furthering the knowledge and teaching practices of embedded system designs by integrating the materials into research or application projects. The research team embraces others who are interested in teaching microcontrollers to enhance collective thought on these topics. The team had designed a common hardware platform for laboratory modules with affordable price to learners which reflects the concepts of active learning. Thus, 
learners are motivated to engage in the activities because they can follow the instructional steps well.

Synchronous instructional tools such as relay chat and video conferencing allows learners to communicate at all time. Asynchronous tools make instructional materials available to learners as long as they have the Internet access. LMS such as Moodle encompasses many available tools for users to view, download, and discuss topics related to subject matter. It created an active learning community for all users. The Moodle dedicated server is used to share knowledge and support the continuous development of teaching and learning practices about developments within the specialty field of microcontroller embedded technology systems. This learning community can provide continuous communication via its listserv for the community and interested groups. In this way, members of the community could share new project ideas and new developments via the community forum. Faculty lessons, laboratory assignments and demonstrations, advanced projects, and chats could be posted. Questions of the unknown for a particular faculty member could be raised and then addressed by other members in the community. Additional professional development teaching lessons could be planned and delivered via the Adobe Connect technologies as new modules are developed by community members. This overall outcome of the continuation of explorations in teaching microcontroller embedded systems has achieved as envisioned by the project team.

The use of distance learning technologies can be adapted to the delivery of engineering technical laboratory courses. It is important to analyze the outcomes that are intended to achieve at the end of the course, identify technological resource available to implement the course online, overcome hardware/software platform issues and design and develop activities with active learning strategies in mind.

\section{References}

1. Lewis, L., K. Snow, E. Farris, and D. Levin. 1999. “Distance Education at Postsecondary Institutions: 1997-98 (NCES) 2000-013.” Washington, DC: National Center for Education Statistics.

2. Morrison, G.R. and S. M. Ross. 2007. "Designing Effective online Instruction. In R. Luppicini (Ed.), Learning Communities in Online Education.” Charlotte, NC: Information Age Publishing: 75-85.

3. Hsiung, S., J. M. Ritz and J. Eiland. 2008. "Design and Develop a Cost Effective Microcontroller Training System for Distance Learning Engineering Students.” In Proceedings of the 2008 American Society for Engineering

4. Hsiung, S, Ritz, J. M, Jones, R, Eiland, J. 2010. “Design and Evaluation of a Microcontroller Training System for Hands-on Distance and Campus-Based Classes.” Journal of Industrial Technology 2010; 26(3): 2-8.

5. Hsiung, S, Hackworth, J, Ritz, J. M, Eiland, J. "Designing a Microcontroller Training Platform for Active Distance Learning Engineering and Technology Students.” Journal of Engineering Technology 2009; 26(2): 32-4

6. Lee, J, Busch, P. E. “Factors related to instructors' willingness to participate in distance education.” Journal of Educational Research 2005; 99(2): 109-115.

7 Microchip. 2015. Technology Inc., Development Tools. Accessed January 20, 2015. http://www.microchip.com/stellent/idcplg?IdcService=SS_GET_PAGE\&nodeId= 1406\&dDocName=en021545

8. Keenan, Daniel S. "Factors that Influence Learning Satisfaction Delivered by Video Streaming Technology.” Journal of Interactive Instruction Development 2011; 22 (1): 3-19.

9. NXP. 2015. NXP LPCXpresso NXP Inc., LPCX Platform. Accessed January 26, 2015. http://www.lpcware.com/lpcxpresso 